\title{
Dynamic Analysis of Two Link Robot Manipulator for Control Design Using PID Computed Torque Control
}

\author{
Jolly Atit Shah*, S S Rattan** \\ * Mechanical Department, National institute of technology, India \\ ** Mechanical Department, NIT, Kurukshetra, India
}

\begin{tabular}{l}
\hline \hline Article Info \\
\hline Article history: \\
Received Sep 24, 2016 \\
Revised Nov 10, 2016 \\
Accepted Nov 26, 2016 \\
\hline
\end{tabular}

\section{Keyword:}

Computed torque control Dynamic control PID Robot manipulator Simulation

\begin{abstract}
The Due to their advantage of high speed, accuracy and repeatability, robot manipulators have become major component of manufacturing industries and even now a days they become part of routine life. Two link robot manipulator is a very basic classical and simple example of robot followed in understanding of basic fundamentals of robotic manipulator. The equation of motion for two link robot is a nonlinear differential equation. For higher degrees of freedom, as the closed form solutions are very difficult we have to use numerical solution. Here we focused mainly on control of robot manipulator to get the desired position using combination of two classical methods PID and computed torque control method after deriving the equation of motion. For the same simulation is represented using MATLAB and compared with computed torque control method.
\end{abstract}

Copyright $(0) 2016$ Institute of Advanced Engineering and Science. All rights reserved.

\section{Corresponding Author:}

Jolly Atit Shah,

National institute of technology, India,

Email: jollyshah80@yahoo.com

\section{INTRODUCTION}

It is well known that robot manipulators are highly nonlinear, dynamically coupled and time-varying systems which are extensively used in industries. The robotic manipulators are generally subjected to uncertainties [1]. Because of these uncertainties and nonlinear behavior, it's a challenging task to control the motion of robot manipulator at accurate position. For the accurate work any robot has to follow predefined trajectories as close as possible. Which makes trajectory tracking control a most important task in control of robotic manipulator [2].

Looking to the above control requirement of robotic manipulator, researches have been reported on robotic control methods such as proportional-integration-derivative (PID) control [3],PD control, PI control[3], feed-forward compensation control [4], adaptive control [5], variable structure control [6], computed torque control[4].In recent years, much attention has been paid to the use of PID control and computed torque control individually for robotic manipulators.

Two degree of freedom robot manipulator acts like human arms. Though human arm is a 7 DOF but to understand the complexity of human arms it's very easy to take example of two degree of freedom robot manipulator movement [7] initially and then attach gripper with it to make it like human arm. The total energy which is sum of kinetic energy and potential energy of the two link system are defined and used to form Lagrangian equations. Finally to define the torque applied on each link these equations are used $[8,9,10]$ 


\section{DYNAMICS OF TWO-LINK MANIPULATORS}

Here for the analysis purpose we had used two degree of freedom planer robot manipulator shown in Figure 1. Let us introduce the following notations:

$\mathrm{q}_{\mathrm{i}}$ - The joint angle of the joint $\mathrm{i}$,

$\mathrm{m}_{\mathrm{i}}$ - The mass of link $\mathrm{i}$,

$l_{i}$ - The length of link $i$,

$\mathrm{g}$ - The gravitational acceleration.

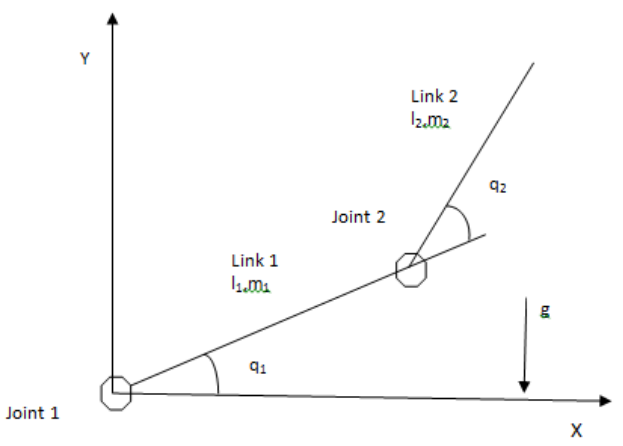

Figure 1. Two Degree of Freedom Robot manipulator

The forward kinematics equations for 2-DOF robotic manipulator have been derived as [8]:

$$
\begin{aligned}
& x=l_{1} * \cos q_{1}+l_{2} * \cos \left(q_{1}+q_{2}\right) \\
& y=l_{1} * \sin q_{1}+l_{2} * \sin \left(q_{1}+q_{2}\right)
\end{aligned}
$$

In order to simplify we assume that the center of mass of each link is right at the middle of the link. We will also assume that the gravitational force acts in the negative direction of the $\mathrm{Y}$ axis. Let us choose $\mathrm{q}=($ $\left.q_{1}, q_{2}\right)^{\mathrm{T}}$ as the generalized coordinates and denote $\mathrm{T}$ the kinetic energy, $\mathrm{P}$ the potential energy and $\mathrm{L}=\mathrm{T}-\mathrm{P}$ the Lagrangian function. Using the notations above and taking into account the assumption that we have made, the kinetic energy and potential energy of the system can be expressed as follows:

$$
\begin{aligned}
& K E=T=\frac{1}{2}\left(m_{1}+m_{2}\right) l_{1}^{2} \dot{q}_{1}^{2}+\frac{1}{2} m_{2} l_{2}^{2} \dot{q}_{2}^{2}+m_{2} l_{1} l_{2} \dot{q}_{1} \dot{q}_{2} \cos \left(q_{1}-q_{2}\right) \\
& P E=P=m_{1} g l_{1} \sin q_{1}+m_{2} g\left(l_{1} \sin q_{1}+l_{2} \sin q_{2}\right)
\end{aligned}
$$

The equations of motion for this manipulator are,

$$
\frac{d}{d t}\left(\frac{\partial L}{\partial \dot{q}_{l}}\right)-\frac{\partial L}{\partial q_{i}}=\tau_{i} \quad \text { where } \mathrm{i}=1,2
$$

Substituting $\mathrm{P}$ and $\mathrm{T}$ in the formula of $\mathrm{L}$ the dynamics equation of the two-link robot manipulator [9]:

$$
\begin{aligned}
& \tau_{1}=m_{2} l_{2}^{2}\left(\ddot{q}_{1}+\ddot{q}_{2}\right)+m_{2} l_{1} l_{2} c_{2}\left(2 \ddot{q}_{1}+\right. \\
& \left.\ddot{q}_{2}\right)+\left(m_{1}+m_{2}\right) l_{1}^{2} \ddot{q}_{1}-m_{2} l_{1} l_{2} s_{2} \dot{q}_{2}^{2}- \\
& 2 m_{2} l_{1} l_{2} s_{2} \dot{q}_{1} \dot{q}_{2}+m_{2} l_{2} q s_{12}+\left(m_{1}+\right. \\
& \left.m_{2}\right) l_{1} g s_{1}+v_{1} \dot{q}_{1}+k_{1} \\
& \tau_{2}=m_{2} l_{2}^{2}\left(\ddot{q}_{1}+\ddot{q}_{2}\right)+m_{2} l_{1} l_{2} c_{2}\left(\ddot{q}_{1}\right)+m_{2} l_{1} l_{2} s_{2} \ddot{q}_{1}^{2}+m_{2} l_{2} g s_{12}+v_{2} \dot{q}_{2}+k_{2}
\end{aligned}
$$

where $\mathrm{c}_{1}=\cos \left(\mathrm{q}_{1}\right), \mathrm{s}_{1}=\sin \left(\mathrm{q}_{1}\right), \mathrm{s}_{12}=\sin \left(\mathrm{q}_{1}+\mathrm{q}_{2}\right), \mathrm{c}_{2}=\cos \left(\mathrm{q}_{2}\right), \mathrm{s}_{2}=\sin \left(\mathrm{q}_{2}\right)$ 
Which can be rewritten as [10],

$$
M(q) \ddot{q}+v(q, \dot{q}) \dot{q}+G(q)=\tau
$$

The parameters $\mathrm{v}_{\mathrm{i}}$ and $\mathrm{k}_{\mathrm{i}}$ are viscous and Coulomb friction coefficients, respectively.

The equation can be written in the form of

$$
\tau=M \ddot{q}+V \dot{q}+F q+G+\tau_{d}
$$

where

$$
\left.\begin{array}{c}
M=\left[\begin{array}{ll}
M_{11} & M_{12} \\
M_{21} & M_{22}
\end{array}\right] \\
M_{11}=m_{1} l_{1}^{2}+m_{2}\left[l_{1}^{2}+l_{2}^{2}+2 l_{1} l_{2} \cos \left(q_{2}\right)\right] \\
M_{12}=M_{21}=m_{2} l_{1} l_{2} \cos \left(q_{2}\right)+m_{2} l_{2}^{2} \\
M_{22}=m_{2} l_{2}^{2} \\
V=\left[\begin{array}{cc}
-h \dot{q}_{2} & -h \dot{q}_{1}-h \dot{q}_{2} \\
h \dot{q}_{1} & 0
\end{array}\right], \operatorname{with} h=m_{2} l_{1} l_{2} \sin \left(q_{2}\right) \\
F=\left[\begin{array}{l}
F_{1} \\
F_{1}
\end{array}\right]=\left[\begin{array}{l}
v_{1} \dot{q_{1}} \\
v_{2} \dot{q}_{2}
\end{array}\right] \\
G_{2}
\end{array}\right]=\left[\begin{array}{c}
m_{1} l_{1} g \cos \left(q_{1}\right)+m_{2} g\left[\begin{array}{l}
l_{2} \cos \left(q_{1}+q_{2}\right)+l_{1} \cos \left(q_{1}\right) \\
m_{2} l_{2} g \cos \left(q_{1}+q_{2}\right)
\end{array}\right] \\
\tau \mathrm{d}=\left[\begin{array}{l}
\tau_{\mathrm{d} 1} \\
\tau_{\mathrm{d} 2}
\end{array}\right]=\left[\begin{array}{l}
\mathrm{k}_{1} \operatorname{sgn}\left(\dot{q_{1}}\right) \\
\mathrm{k}_{2} \operatorname{sgn}\left(\dot{q_{2}}\right)
\end{array}\right]
\end{array}\right.
$$

\section{DESIGN STEPS FOR PID COMPUTED TORQUE CONTROL OF ROBOT MANIPULATORS}

Any mechanical system having translation motion is described as below shown in Figure 2 .

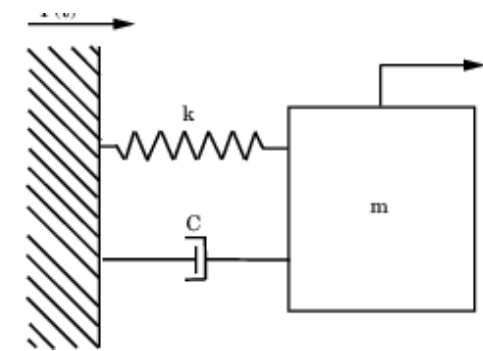

Figure 2. Mechanical system with translational motion

Open loop dynamic equation for such type of system will be given by following equation,

$$
f=m x^{*}+b x+k x
$$

\section{step 1}

Assuming that we don't know value of $\mathrm{m}, \mathrm{b}, \mathrm{k}$.

In model based control method $\mathrm{m}, \mathrm{b}, \mathrm{k}$ are calculated using real time calculations. Thus system will be simplified to mass only system. Applying model based control law to equation (10) become, 


$$
\mathrm{f}=\mathrm{mf}_{\mathrm{s}}+\mathrm{bx}+\mathrm{kx}
$$

where $f_{s}=x "$, which is new input to system as shown in Figure 3 on next page.

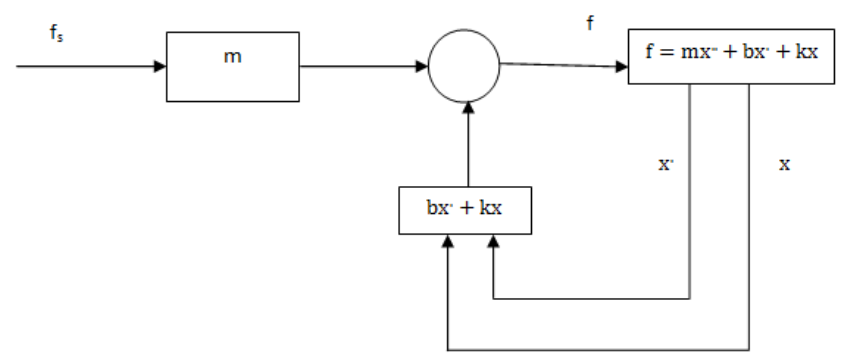

Figure 3. Structure of computer torque control

\section{Step 2}

Apply any classical control law like PD, PI, PID.

If we apply servo control law to above equation, it will get converted into computed torque control system. To improve the accuracy we will use feedback control. Computed torque control along with PID feedback control is known as PID computed torque control method. Total system block diagram is shown below in Figure 4.

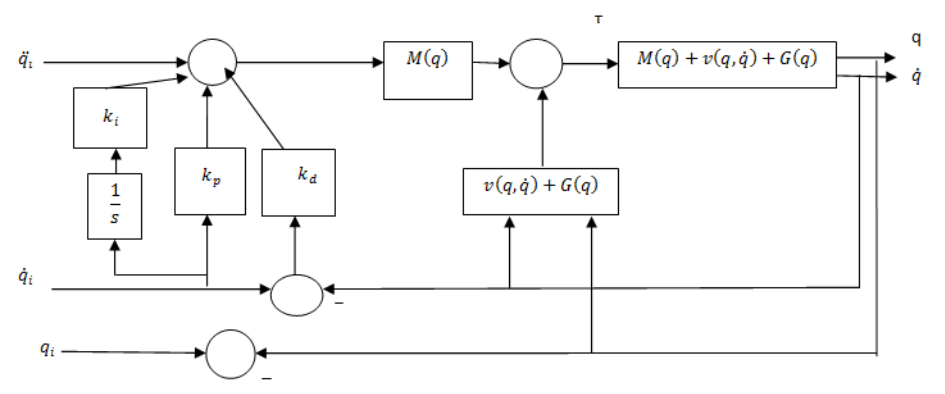

Figure 4. PID feedback loop computed torque controller

thus total control law is defined as,

$$
\tau=M(q)\left(\ddot{q}_{d}+k_{d} \dot{e}+k_{p} e+k_{i} \varepsilon\right)+V(q, \dot{q})+G(q)
$$

where $\varepsilon(t)$ is integral of tracking error $\mathrm{e}(\mathrm{t})$ and $\mathrm{k}_{\mathrm{d}}, \mathrm{k}_{\mathrm{p}}, \mathrm{k}_{\mathrm{i}}$ are control gain.

\section{SIMULATION AND RESULTS}

For simulation purpose following values are taken in MATLAB Programming.

Total Simulation Time $=\mathrm{T} 1=10 \mathrm{sec}$ and $\mathrm{T} 2=120 \mathrm{sec}$;

Sampling Time $=\mathrm{T}=0.002 \mathrm{sec}$;

mass $=\mathrm{m}=[2 ; 2]$ unit;

$11=1$ unit;

$12=1$ unit;

grav $=9.8$ unit;

Gains:

$\mathrm{Kd}=\left[\begin{array}{lll}1000 & 0 ; 0 & 1000]\end{array}\right]$

$\mathrm{Kp}=[100$ 0;0 100];

$\mathrm{Ki}=[100 ; 010]$; 
Simulation is done to confirm the results of the proposed control scheme. Simulation is done for first $10 \mathrm{sec}$ and then for second time $120 \mathrm{sec}$, and at every $0.002 \mathrm{sec}$ the sample reading was taken to plot the graphs. Figure 5 shows the position errors for joint 1 and joint 2 for $10 \mathrm{sec}$ and Fig. 6 shows the velocity errors for joint 1 and joint 2 for $10 \mathrm{sec}$.

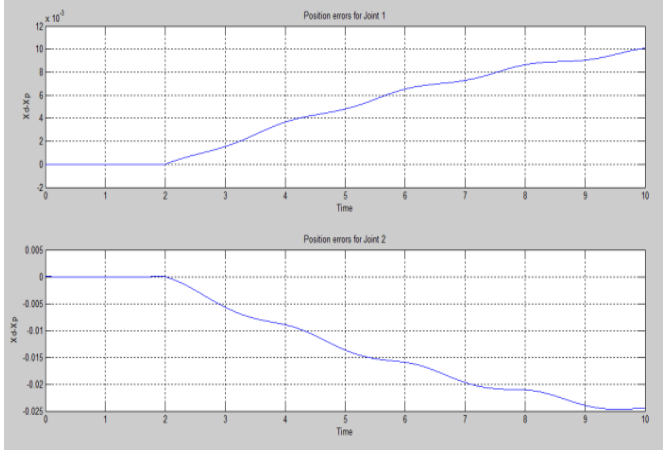

Figure 5. Position errors for joint 1 and joint 2 for $10 \mathrm{sec}$

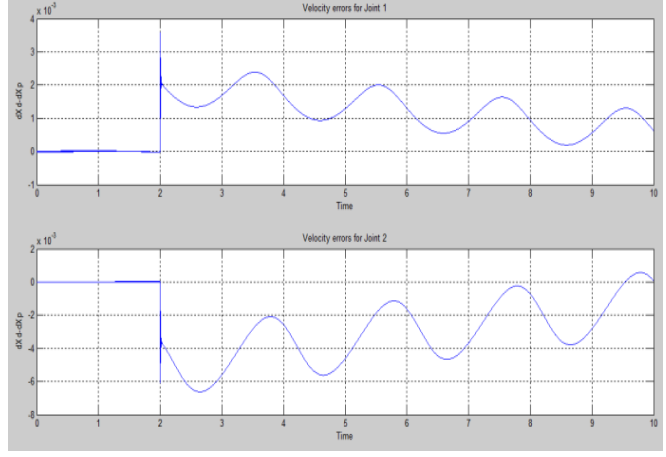

Figure 6. Velocity errors for joint 1 and joint 2 for $10 \mathrm{sec}$

Figure 7 and Figure 8 shows the comparison for derived and predicted position for link 1 and link 2 respectively for $10 \mathrm{sec}$. Figure 9 shows the torque required for joint 1 and joint 2 for control purpose for 10 sec.

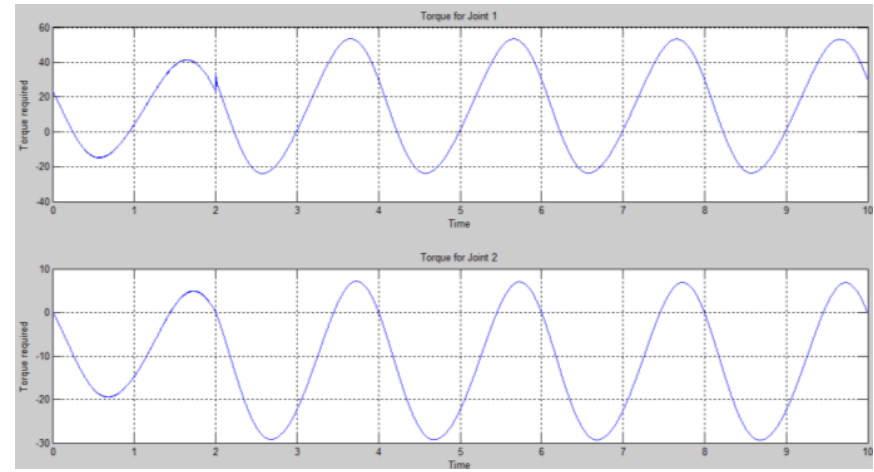

Figure 9. Torque required for joint 1 and joint 2 for $10 \mathrm{sec}$.

Figure 10 shows the position errors for joint 1 and joint 2 for $120 \mathrm{sec}$ and Figure 11 shows the velocity errors for joint 1 and joint 2 for $120 \mathrm{sec}$.

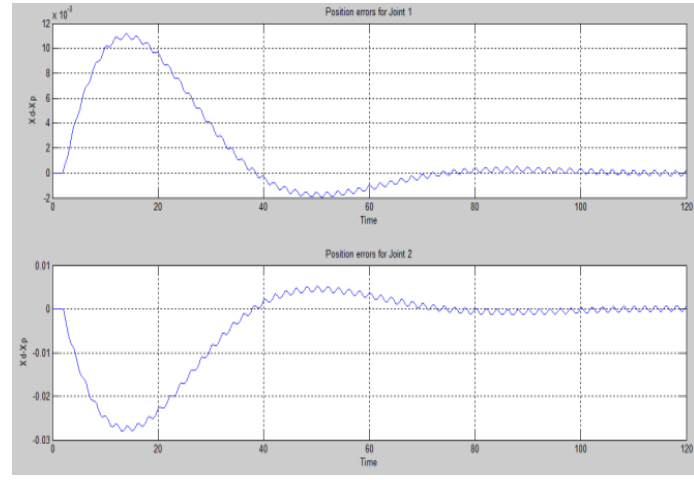

Figure 10. Position errors for joint 1 and joint 2 for $120 \mathrm{sec}$

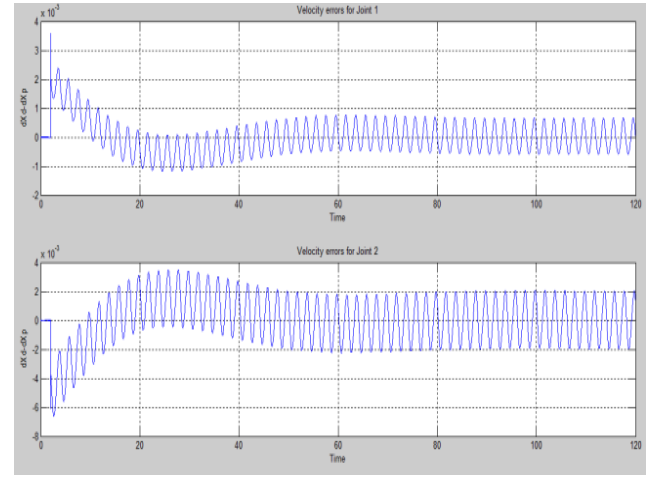

Figure 11. Velocity errors for joint 1 and joint 2 for $120 \mathrm{sec}$ 
Figure12 and Figure13 shows the comparison for derived and predicted position for link 1 and link 2 respectively for $120 \mathrm{sec}$.

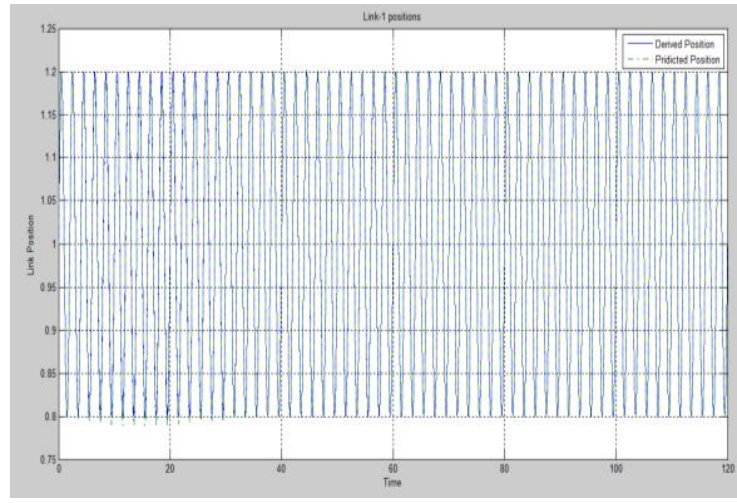

Figure 12. Comparison of derived and predicted position for link 1 for $120 \mathrm{sec}$.

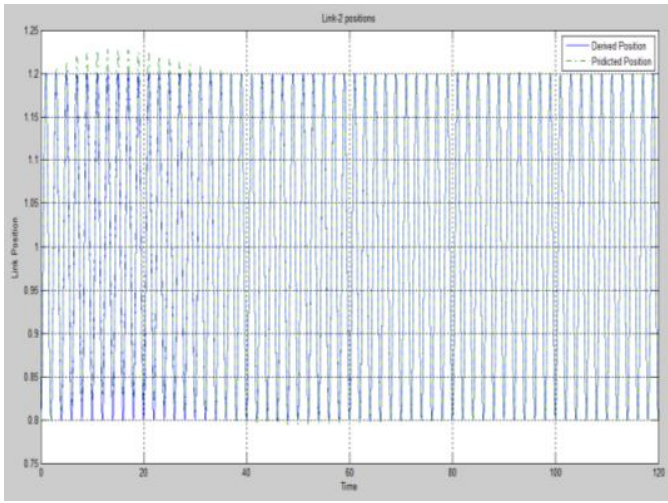

Figure 13. Comparison of derived and predicted position for link 2 for $120 \mathrm{sec}$.

Figure 14 shows the torque required for joint 1 and joint 2 for control purpose for 120 sec.

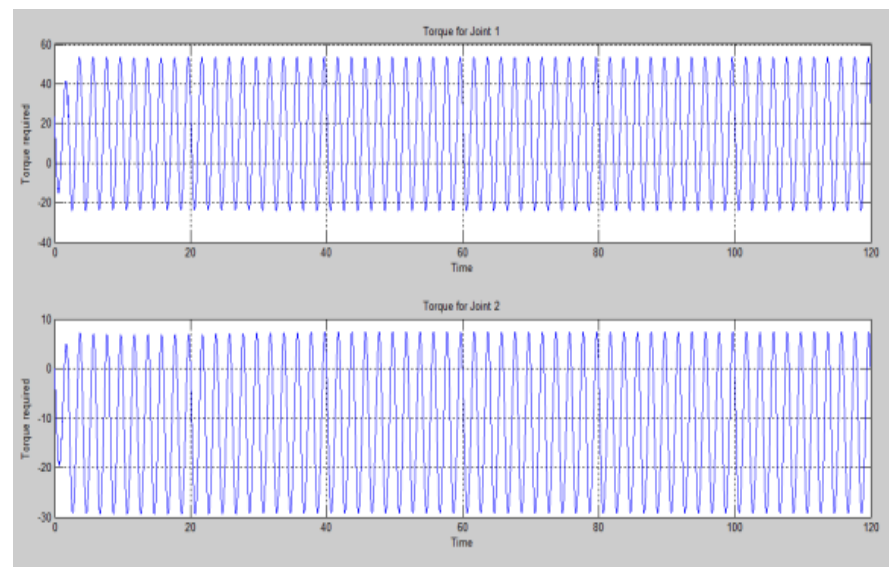

Figure 14. Torque required for joint 1 and joint 2 for $120 \mathrm{sec}$.

\section{CONCLUSION}

In this paper we aimed to introduce a new controller system with the help of two conventional controller PID and Computer torque control. The simulation results show the validity of the proposed method and give the possibility of a PID computed torque control for 2 DOF robot manipulator. Position errors and Velocity errors are coming to be less than 1\%. And even after few seconds those are getting almost around zero as shown in simulation graphs. Simulations graphs also shows that error between derived and predicted position for link 1 and link 2 is almost around zero.

\section{REFERENCE}

[1] Amol A. Khalate, Gopinathan Leena, Goshaidas Ray, An Adaptive Fuzzy Controller for Trajectory Tracking of Robot Manipulator, Intelligent Control and Automation, 2011, 364-370

[2] Koren Ward, Rapid Simultaneous Learning of Multiple Behaviours with a Mobile Robot, Proc. 2001, Australian Conference on Roboics and Automation, Sydney, 14-15 Nov 2001

[3] J.Y.S. Luh, Conventional controller design for Industrial robots-a tutorial, IEEE Trans. Systems Man Cybernet. 1983, 298-316. 
[4] Pradeep K. Khosla, Takeo Kanade, Experimental of Evaluation of Nonlinear Feedback and Feedforward Control Schemes for Manipulators, The International Journal of Robotirs Research, Vol. 7, No. 1, February 1988.

[5] J.J.E. Slotine, W. Li, Adaptive Manipulator Control: A Case Study, IEEE Trans. Automat. Control 33, $1988,995-1003$

[6] Mark W.Spong and M.Vidyasagar, Robot Dynamics and control, John Wiley \& Sons,2004.

[7] John M Hollerbach, Computer, Brains and the Control Movement, Manchester Institute of Technology, Artificial Intelligence Laboratory, June 1982

[8] Jolly Shah, Dr. S.S.Rattan, Prof. B. C. Nakra, Kinematic Analysis of a Planer Robot Using Artificial Neural Network, International Journal of Robotics and Automation, September 2012, 145-151.

[9] Stephen Dodds, A two-link manipulator: simulation and control design Advisor: Dr. Mahboub Baccouch, University of Nebraska at Omaha Omaha, NE, 68134, March 2012

[10] Duy Nguyen-Tuong, Jan Peters, Learning Robot Dynamics for Computed Torque Control using Local Gaussian Processes Regression, ECSIS Symposium on Learning and Adaptive Behaviors for Robotic Systems, 2008 